\title{
Principialismo no exercício da medicina e em processos ético-profissionais
}

Marina Faria Salomão ${ }^{1}$, Luiza Ribeiro Gontijo ${ }^{1}$, Luisa Abdo Ramos Nunes ${ }^{1}$, Felipe Pueyo Magalhães ${ }^{1}$, José Helvécio Kalil de Souza ${ }^{1}$, Roberto Paolinelli de Castro $^{2}$

1. Faculdade de Minas, Belo Horizonte/MG, Brasil. 2. Pesquisador autônomo, Belo Horizonte/MG, Brasil.

\begin{abstract}
Resumo
Este estudo objetiva mostrar a importância dos princípios bioéticos de Beauchamp e Childress e reafirmá-los na prática médica a fim de diminuir os números exorbitantes de processos ético-profissionais impetrados por iatrogenia. Além disso, busca-se elucidar as fases do processo de modo a informar a comunidade médica sobre seu andamento. Para tal, realiza-se atualização bibliográfica pautada no Código de Ética Médica, no Código de Processo Ético-Profissional e em guias práticos e dinâmicos aplicados aos princípios da bioética. Conclui-se que o exercício da medicina pautado na ética, além de ser justo e benéfico ao paciente, é também modo de resguardar o profissional de possíveis interpretações equivocadas sobre sua conduta.
\end{abstract}

Palavras-chave: Códigos de ética. Direitos civis. Bioética. Ética baseada em princípios.

\section{Resumen}

\section{Principialismo en la práctica de la medicina y en los procesos ético-profesionales}

El objetivo de este estudio es mostrar la importancia de los principios bioéticos de Beauchamp y Childress y reafirmarlos en la práctica médica, con el fin de reducir la exorbitante cantidad de procesos ético-profesionales provocados por la iatrogenia. Además, se busca dilucidar las fases del proceso ético-profesional para informar a la comunidad médica. Para ello, se realiza una actualización bibliográfica con base en el Código de Ética Médica, el Código de Proceso Ético-Profesional y guías prácticas y dinámicas aplicadas a los principios de la bioética. Se concluye que la práctica de la medicina basada en la ética, además de justa y beneficiosa para el paciente, también protege al profesional de posibles malas interpretaciones sobre su conducta.

Palabras clave: Códigos de ética. Derechos civiles. Bioética. Ética basada en principios.

\section{Abstract \\ Principlism in medical practice and ethical-professional lawsuits}

This study aims to show the importance of the bioethical principles of Beauchamp and Childress, contributing to reiterate them in medical practices to reduce the exorbitant numbers of professional lawsuits brought about by iatrogenesis. Furthermore, the text tries to elucidate the phases these litigations undergo to give more information on the subject to the medical community. To this end, this research carries out a bibliographic review encompassing the Code of Medical Ethics, the Code of Ethical-Professional Litigation, as well as practical and modifiable resources applied to bioethical principles. We conclude that, besides being fair and beneficial to the patient, the practice of ethics-based medicine also serves to protect professionals from misinterpretations regarding their conduct.

Keywords: Codes of ethics. Civil rights. Bioethics. Principle-based ethics.

Declaram não haver conflito de interesse. 
Este trabalho foi motivado pela observação do alto número de processos éticos a que médicos têm respondido. Essas litigâncias podem ser evitadas com medidas relacionadas ao respeito pelo paciente, que, contudo, parecem ter sido "esquecidas" pelos profissionais, de modo que é necessário reafirmá-las. O próprio Código de Ética Médica (CEM) ${ }^{1}$ já é boa base para compreender e executar tais medidas para evitar processos ético-profissionais (PEP).

Percebe-se, no entanto, que a literatura sobre a temática médico-jurídica, bem como sobre o $\mathrm{CEM}^{1}$ e o Código de Processo Ético-Profissional (CPEP) ${ }^{2}$, não é suficiente para instruir o tema, devido à pouca relação entre direito e medicina. Somada a essa carência, constata-se que, apesar da óbvia demanda, não há guias práticos e dinâmicos que promovam a aplicação de princípios bioéticos e ajudem a evitar a instauração de PEP. Dessa forma, sentiu-se a necessidade de desenvolver estudo em que confluam todas essas preocupações e que sirva de fonte de informação para a classe médica, embasando a prática.

Os estudos sobre ética em pesquisa historicamente respondem a barbaridades como o desastre de Lübeck, em 1930, o estudo da sífilis não tratada de Tuskegee, em 1932, e todos os crimes cometidos durante a Segunda Guerra Mundial que alegavam visar o progresso das ciências ${ }^{3,4}$. As lacunas desses estudos, porém, deixavam claro que aquilo que os gregos chamavam de "filosofia da moral" exigia pareceres mais imediatos. Dos primeiros registros do termo "bioética" até a formação de campo específico do conhecimento propriamente dito, inúmeros códigos e publicações foram produzidos, mas somente em 1979, na obra clássica de Beauchamp e Childress, Principles of biomedical ethics ${ }^{5}$, foram descritos os princípios básicos que hoje regem a bioética: beneficência, não maleficência, autonomia e justiça.

Por que continuar discutindo a moralidade da profissão médica se ela já está descrita? A resposta a esse questionamento remete à comparação entre a prática médica ideal e aquela realmente aplicada. Além disso, em contexto de extrema judicialização como o atual, basear-se nesses princípios é forma de médicos e profissionais da área da saúde se resguardarem, respeitando o direito do paciente como ser ativo no processo assistencial, tratando-o de modo digno, procurando terapêuticas que the tragam benefícios e ponderando sempre a linha tênue entre avanço terapêutico e processo lesivo à qualidade da vida. Médicos convivem diariamente com adversidades e desfechos imprevisíveis que fogem ao controle científico, e nesses casos de incerteza é necessário aprender a tomar decisões morais.

Entretanto, as atitudes profissionais nem sempre são claras para o paciente e, nesse sentido, sua insatisfação é justificável. Processos ético-profissionais são necessários para fiscalizar e denunciar atos negligentes, imprudentes e de imperícia médica, mas o número dessas demandas impetradas por insatisfação com a assistência tem se mostrado muito elevado. Para reduzi-lo, é preciso reafirmar os princípios da bioética e colocá-los em prática. Ajustes simples da conduta dos profissionais, com base em tais princípios, já mudariam o olhar do paciente para $\mathrm{o}$ atendimento.

Além disso, trâmites e etapas jurídicas são confusos para o trabalhador da saúde, o que tende a deixá-lo ainda mais inseguro e ansioso com a situação. Assim, seria útil elaborar guia simplificado sobre o curso do processo, baseado no CPEP ${ }^{2}$, de modo a esclarecer seu andamento para a comunidade médica.

Trata-se de tema extremamente importante para o exercício da medicina e, diante do exposto, a intenção deste artigo é analisar a incidência de processos éticos-profissionais de acordo com dados do Superior Tribunal de Justiça (STJ) e, a partir dessa análise, discorrer sobre a ética na prática médica de modo a refletir sobre os motivos do número exacerbado de processos. Para isso, relaciona-se a abordagem jurídica e bioética na busca por entender o máximo possível de questões relacionadas ao tema e elucidar o curso legal do PEP.

\section{Materiais e método}

Este estudo é atualização bibliográfica realizada durante o primeiro semestre de 2019. A fonte de pesquisa foi o banco de dados do STJ, com processos referentes ao período de 2000 a $2014^{6}$. Também foram analisados o $\mathrm{CEM}^{1}$ e o $\mathrm{CPEP}^{2}$, ambos disponíveis no site do Conselho Federal de Medicina (CFM), e artigos relevantes no campo da ética e da bioética, buscados na Scientific Electronic Library Online. Foram considerados os artigos que, após análise, mostraram-se relevantes do ponto de vista da qualidade da abordagem e da apresentação de dados estatísticos relevantes. 


\section{Dados do Superior Tribunal de Justiça}

Atos iatrogênicos ainda acontecem com bastante frequência. Segundo o escritório de advocacia Assis Videira ${ }^{6}$, dados do STJ indicam aumento substancial, maior que $300 \%$, no número de processos instaurados por erro médico entre 2001 e 2011, além de aumento de $180 \%$ nas condenações. Só em 2014 foram 299 processos abertos, 173 sentenças e 1.212 processos em transição apenas no estado de Minas Gerais ${ }^{6}$. Entre as consequências mais reclamadas judicialmente estão morte, danos estéticos, necessidade de novas cirurgias e perda de órgão ou de função do organismo. Dentre as especialidades, as mais demandadas no STJ são ginecologia/obstetrícia, traumato-ortopedia e cirurgia plástica ${ }^{6}$.

De 2013 a 2015 houve aumento de 11,2\% dos processos em Minas Gerais, com 50,2\% de absolvições ${ }^{6}$, dados que indicam fenômeno crescente e assustador para a profissão: a medicina como principal alvo da indústria jurídica do dano ${ }^{7}$. Segundo Miguel Kfouri Neto ${ }^{8}, 80 \%$ das ações contra médicos são julgadas improcedentes, o que evidencia a intenção de proteger o paciente visando reparações por danos morais, em busca de lucro. Nesse contexto, não se levam em consideração desfechos que o exercício da medicina pode trazer ao paciente, e a evolução natural do quadro pode ser equivocadamente interpretada como negligência.

As consequências da judicialização (perdas financeiras, prejuízos ao nome e à honra, exposição à imprensa sensacionalista) mostram a necessidade de levá-la a sério e buscar preveni-la. No presente estudo, a análise de processos e denúncias mais frequentes levou à conclusão de que reafirmar e entender princípios éticos como condutores da prática médica são uma das formas mais importantes de prevenção. O exercício da medicina pautado na ética, além de beneficiar o paciente e ser justo, protege o profissional de interpretações equivocadas sobre sua conduta.

\section{Beneficência}

Um dos princípios fundamentais do CEM dita que o médico guardará absoluto respeito pelo ser humano e atuará sempre em seu benefício, mesmo depois da morte. Jamais utilizará seus conhecimentos para causar sofrimento físico ou moral, para o extermínio do ser humano ou para permitir e acobertar tentativas contra sua dignidade e integridade 9 . Na mesma linha, o profissional médico invoca o juramento hipocrático quando se forma: aplicarei os regimes para o bem do doente segundo o meu poder e entendimento, nunca para causar dano ou mal a alguém ${ }^{10}$.

Esses dizeres deveriam fazer parte do dia a dia de todos os profissionais da saúde, tendo sempre como objetivo o completo bem-estar do paciente. Exemplos simples de prática da beneficência podem ser observados quando o médico se mostra atento ao paciente e a seus sinais como um todo, ou quando o médico entende o que o paciente expressa - tanto o que ele escolhe mostrar quanto o que fica subentendido, considerando o cenário social e cultural em que o indivíduo se encontra. Em caso de discordância de opiniões, o dever do médico é aconselhar o paciente a seguir o caminho com mais pontos positivos que negativos, maximizando benefícios e minimizando danos. Harmonizando beneficência e paternalismo, o médico deve manter sua autoridade, preservando conhecimentos e responsabilizando-se pela tomada de decisão. O paciente, por sua vez, deve fazer sua escolha de acordo com as informações recebidas e seus valores pessoais ${ }^{11}$.

\section{Não maleficência}

O médico deve evitar danos ao paciente, princípio consagrado no aforismo hipocrático primum non nocere (primeiro, não prejudicar). Mergulhando na história antiga, é interessante citar que, antes de Hipócrates, Sócrates defendia que aquele que praticava o mal o fazia por não conhecer a prática do bem ${ }^{12}$. Aplicando essa ideia ao exercício da medicina, pode-se dizer que o profissional que age contra o princípio da não maleficência e consequentemente traz prejuízos à saúde do paciente - mostra ignorância e desconhecimento ${ }^{12}$.

Certas terapêuticas e ações diagnósticas podem causar desconforto ou malefícios secundários aos pacientes. Assim, cabe sempre ao profissional se resguardar e avaliar a real necessidade dos procedimentos. Geralmente, a reflexão sobre a beneficência envolve a decisão de executar determinada técnica, enquanto o princípio da não maleficência envolve a possibilidade de se abster dela ou limitá-la. Como 
impasse no pensamento ético da abstenção, a teoria moral do duplo efeito deve ser incluída como questionamento: "devo causar dano visando o benefício maior?" Exemplo clássico é o risco elevado do tratamento para a doença de Hodgkin - que, contraposto às pequenas chances de sobrevivência do paciente sem tratamento, permite que se conclua pelo caráter relativo do princípio da não maleficência ${ }^{13}$.

A discussão sobre esse princípio é extensa e complexa. Outro de seus aspectos relaciona-se ao direito à morte digna, que ainda é tabu, e por isso mesmo deveria ser amplamente debatido. $O$ trabalho do médico é, sem dúvida, curar e focar suas ações diagnósticas e terapêuticas no doente, mas é também seu dever reconhecer o limite e a finitude de cada ser. Logo, faz parte da jornada profissional dialogar abertamente com a família e questionar a obstinação terapêutica. Não causar o mal, nesse caso, é poupar o paciente de uma existência sem qualidade e mantida apenas por máquinas ${ }^{14}$.

\section{Autonomia}

Em seu artigo 31, o CEM veda ao médico desrespeitar o direito do paciente ou de seu representante legal de decidir livremente sobre a execução de práticas diagnósticas ou terapêuticas, salvo em caso de iminente risco de morte ${ }^{15}$. "Autonomia" é a possibilidade de escolher, sem coação interna ou externa, entre as alternativas apresentadas. O paciente, exceto quando em risco iminente de morte, deve ter total liberdade para decidir a que procedimentos está disposto a se submeter, passando o direito ao seu representante legal caso o enfermo não esteja capacitado a escolher.

Para respeitar a autonomia, o médico deve se lembrar que o paciente tem voz: qualquer pessoa no controle de suas faculdades mentais tem o direito de escolher o tratamento a que será submetida, e de forma alguma pode ser objeto de negligência, discriminação, violência ou crueldade. As decisões devem ser tomadas em conjunto com o paciente ou, em alguns casos, com seu responsável legal, considerando todos os pontos de vista possíveis e admitindo que pode haver mudanças na conduta a ser tomada.

É de extrema importância registrar todas as informações em prontuário de forma a evidenciar as condutas adotadas e permitir sua futura consulta, se necessário. Além disso, em todos os procedimentos deve-se utilizar o termo de consentimento livre e esclarecido ${ }^{16}$, explicando cada passo ao enfermo e a seus familiares ou responsáveis, inclusive quando o tratamento sugerido pelo profissional de saúde é recusado.

\section{Justiça e equidade}

É difícil distinguir o princípio da justiça do de equidade, uma vez que ambos derivam da obrigação ética de tratar cada indivíduo conforme o que é moralmente correto e dar a cada um o que Ihe é devido. Ser ético, nesse sentido, é atuar e trabalhar para uma relação médico-paciente saudável, independentemente de aspectos culturais, sociais, financeiros ou religiosos. Ser justo é oferecer conhecimentos e recursos de modo imparcial, sem direcioná-los apenas a grupos específicos. É importante que o paciente sinta a dedicação do profissional e sua curiosidade em relação ao relato, recebendo a devida atenção ${ }^{17}$.

A efetivação desses princípios na prática médica é questão delicada, visto que a justiça e a equidade ainda estão longe de ser aplicadas socialmente no Brasil. Assim, uma assistência equânime só deixará de ser utópica quando a sociedade deixar de apresentar tantas desigualdades ${ }^{17}$. Até lá, a prática médica tenta encontrar modos de se adaptar e cumprir normas de conduta.

\section{Processo ético-profissional}

Ainda que atue conforme os princípios do CEM, o médico está sujeito a ações judiciais, pois todo paciente que se sinta prejudicado tem o direito de recorrer à Justiça por meio de sindicância, que pode ser aberta pelo CFM ou por Conselho Regional de Medicina (CRM) a fim de investigar o fato e, se for o caso, dar continuidade ao PEP ${ }^{18}$. Caso tenha agido de acordo com os princípios éticos e ainda assim a sindicância seja aberta, o profissional deve se ater à denúncia propriamente dita e explicar o acontecimento com todas as provas necessárias para desenvolver a defesa prévia ${ }^{19}$. Dentre essas provas incluem-se documentos, justificações e até cinco testemunhas, reunidos com o fito de fornecer o máximo de informações 
para impedir a instauração do PEP $^{19}$. A lei não exige a presença de advogado, mas nesse momento é importante contatar com especialista para elaborar a defesa e apresentar provas.

A sindicância é analisada por câmara específica e, para ser instaurada, deve haver denúncia escrita ou verbal, com identificação completa do denunciante. Essa denúncia é então direcionada ao CRM, onde é avaliada por um corregedor e pode ser arquivada em caso de desistência do denunciante ou a critério da câmara do Conselho, desde que não se trate de possível lesão corporal de natureza grave, assédio sexual ou óbito do paciente. Nesses casos, a sindicância será apreciada de acordo com o Código Penal ${ }^{20}$, e de forma alguma a denúncia anônima será aceita. A responsabilidade ético-profissional é independente da criminal, ou seja, mesmo que se aplique o Código Penal ${ }^{20}$ no julgamento, o PEP seguirá normalmente e o médico estará sujeito às punições profissionais ${ }^{18}$.

Após a instauração da sindicância, o corregedor nomeará um conselheiro fiscal que apresentará relatório sobre a identificação das partes, descrição dos fatos, correlação entre o ocorrido com a infração ao CEM e conclusão indicando existência ou inexistência de infração ao Código ${ }^{18}$. O relatório será encaminhado para análise com o objeto de propor: conciliação; assinatura do termo de ajustamento de conduta (TAC), se pertinente; arquivamento da sindicância, caso não haja indício de infração ao CEM; ou instauração do PEP, cumulada ou não de proposta de interdição cautelar, se forem constatadas evidências de infração ao Código ${ }^{18}$.

A conciliação entre as partes pode ocorrer somente em casos que não tratam de lesão corporal de natureza grave, assédio sexual ou óbito do paciente, e deverá ser proposta por conselheiro sindicante ou outro membro da câmara. Não é permitida proposta de conciliação após aprovação do relatório conclusivo da sindicância, e, caso haja proposta, não caberá qualquer recurso após homologação pela câmara de sindicância. Caso a conciliação não seja bem-sucedida, a sindicância prosseguirá com o TAC ${ }^{18}$.

O TAC refere-se ao ato oficial pelo qual a pessoa física ou jurídica reconhece que sua conduta ofende o interesse ético individual ou coletivo e assume, perante órgão público legitimado, o compromisso de eliminar a ofensa ou o risco por meio da adequação de seu comportamento, cumprindo exigências legais e éticas ${ }^{18}$. $O$ termo, de caráter sigiloso, firma o compromisso do médico em acatar cláusulas obrigatórias, impõe os critérios de comportamento adequado, estabelece a suspensão da sindicância com atenção aos prazos prescricionais e define formas de fiscalização quanto às metas e obrigações assumidas ${ }^{18}$. Cabe ao CRM fiscalizar o cumprimento do TAC, cuja inobservância implica abertura de PEP. O médico que aderir a um TAC ficará impedido de firmar outro termo pelo período de cinco anos ${ }^{18}$.

A interdição cautelar do exercício profissional do médico cuja ação ou omissão está prejudicando ou prestes a prejudicar o paciente ou a população pode ocorrer após votação da maioria do conselho pleno do CRM. A interdição implica impedimento total ou parcial de praticar medicina e tem efeito imediato até o julgamento final do PEP. Ela é válida para todo o território nacional e deve ser publicada em Diário Oficial e nos meios de comunicação dos conselhos de medicina, com identificação das partes, sendo necessário ainda comunicar os estabelecimentos de saúde em que o médico exerce suas atividades. $O$ julgamento do PEP deve ocorrer no prazo de seis meses, prorrogáveis por igual período apenas uma vez ${ }^{18}$.

Após instaurado, o PEP não pode ser extinto por desistência do denunciante - se esse for o caso, o processo seguirá de ofício. O médico denunciado é informado por meio de carta de citação, em que consta seu nome completo, endereço residencial ou profissional, finalidade da citação e prazo e local para apresentação da defesa prévia. Na oportunidade, como já destacado, o denunciado poderá oferecer documentos e justificações, especificar as provas pretendidas e nomear até cinco testemunhas. Serão inadmissíveis provas ilícitas, ou seja, que violem normas constitucionais ou legais ${ }^{18}$.

Intimações são então encaminhadas às testemunhas, às partes e aos advogados. $O$ documento deve conter descrição da pessoa intimada, nota de ciência e local e hora da audiência de instrução, à qual todos devem comparecer e que será iniciada após identificação e qualificação de todas as partes. Ao final da audiência, o julgamento é discutido entre os conselheiros. Chegando a uma conclusão, realiza-se julgamento com a presença exclusiva das partes e dos defensores, de membros do CRM, integrante da assessoria jurídica do CRM e funcionários responsáveis pelo funcionamento do Tribunal de Ética Médica ${ }^{18}$. 
A penalidade infligida ao profissional médico (se houver indicação) é decidida em votação por conselheiros do CRM ou CFM. As penas disciplinares podem ser: 1) advertência confidencial em aviso reservado; 2) censura confidencial em aviso reservado; 3) censura pública divulgada na imprensa oficial; 4) suspensão do exercício profissional por até 30 dias; ou 5) cassação do exercício profissional pelo $\mathrm{CFM}^{18}$.

As duas primeiras penas são privadas (a sociedade não é informada da penalidade aplicada) e serão comunicadas formalmente ao profissional infrator e registradas no prontuário médico relativo à infração. Já as três últimas são divulgadas no Diário Oficial do estado, do Distrito Federal e da União, em jornais de grande circulação e no sítio eletrônico do CRM, além de constar no prontuário do médico faltoso, de modo a informar à sociedade que o profissional sofreu condenação ética. No caso das duas últimas penas, suspensão e cassação, a carteira profissional e a cédula de identidade do médico serão apreendidas. Portanto, quando tem seu exercício profissional cassado e essa penalidade é mantida pelo CFM, o médico não pode mais praticar medicina no Brasil. No entanto, ao receber a sentença, se for inocente ou se estiver insatisfeito com a penalidade, o profissional pode recorrer ao $\mathrm{CFM}^{19}$.

A punição por falta ética prescreve em cinco anos, contados da data do efetivo conhecimento do fato pelo CRM. A sindicância ou o PEP que não estiverem ativos por mais de três anos serão arquivados de ofício ou por requerimento da parte interessada ${ }^{18}$. Já a reabilitação poderá ser requerida pelo médico no CRM onde está inscrito após oito anos do cumprimento da pena e sem que tenha sofrido outra penalidade ético-profissional nesse período, exceto em caso de cassação do exercício profissional ${ }^{18}$.

\section{Considerações finais}

O crescente número de litigâncias relacionadas à prática médica mostra a necessidade de entender e aplicar a bioética principialista, que se baseia em sempre atuar em benefício do paciente, evitando danos, respeitando seus direitos e buscando a equidade. A partir da percepção da complexidade da prática médica, deve-se desenvolver meios que garantam que o atendimento seja cada vez mais ético. Se esses princípios forem seguidos à risca, os profissionais estarão resguardados de sofrer processos que dizem respeito a seu comportamento. Mesmo assim, caso o processo aconteça com consequências que vão desde advertências até cassação do exercício profissional -, é preciso conhecer suas fases e andamento, de modo a manter a calma durante a situação.

\section{Referências}

1. Conselho Federal de Medicina. Código de Ética Médica: Resolução ${ }^{\circ} 2.217$, de 27 de setembro de 2018 , modificada pelas Resoluções CFM n² 2.222/2018 e 2.226/2019 [Internet]. Brasília: CFM; 2019 [acesso 5 fev 2021]. Disponível: https://bit.ly/2MCfsop

2. Conselho Federal de Medicina. Resolução CFM n ${ }^{\circ}$ 2.145, de 17 de maio de 2016. Aprova o Código de Processo Ético-Profissional (CPEP) no âmbito do Conselho Federal de Medicina (CFM) e Conselhos Regionais de Medicina (CRMs). Diário Oficial da União [Internet]. Brasília, p. 329, 27 out 2016 [acesso 5 fev 2021]. Seção 1. Disponível: https://bit.ly/3aB2RcZ

3. Rocha CP. A história da bioética no mundo. Bioét Foco [Internet]. 7 maio 2015 [acesso 20 maio 2019]. Disponível: https://bit.ly/36Lkx4O

4. Lopes JA. Bioética: uma breve história: de Nuremberg (1947) a Belmont (1979). Rev Méd Minas Gerais [Internet]. 2014 [acesso 20 maio 2019];24(2):262-73. DOI: 10.5935/2238-3182.20140060

5. Beauchamp TL, Childress JF. Principles of biomedical ethics. $7^{\mathrm{a}}$ ed. New York: Oxford University Press; 2013.

6. Assis Videira Consultoria \& Advocacia. Dados e estatísticas sobre a judicialização da medicina [Internet]. Belo Horizonte: Assis Videira; 2015 [acesso 23 set 2020]. Disponível: https://bit.ly/3aH2HRk

7. Bernardes A. Médicos processados injustamente. Jus [Internet]. 9 abr 2015 [acesso 8 jun 2019]. Disponível: https://bit.ly/3pTxXDe 
8. Kfouri Neto M. Culpa médica e ônus da prova: presunções, perda de uma chance, cargas probatórias dinâmicas, inversão do ônus probatório e consentimento informado: responsabilidade civil em pediatria, responsabilidade civil em gineco-obstetrícia. São Paulo: Editora dos Tribunais; 2002.

9. Conselho Federal de Medicina. Op. cit. 2019. p. 15.

10. Juramento de Hipócrates. Cremesp [Internet]. [s.d.] [acesso 20 abr 2019]. Disponível: http://bit.ly/3bH1VEr

11. Silva HB. Beneficência e paternalismo médico. Rev Bras Saúde Mater Infant [Internet]. 2010 [acesso 10 jun 2019];10(supl 2):s419-25. DOI: 10.1590/S1519-38292010000600021

12. Conford FM. Antes e depois de Sócrates. São Paulo: Martins Fontes; 2001.

13. Kipper JD, Clotet J. Princípios da beneficência e não maleficência. In: Costa SIF, Garrafa V, Oselka G, organizadores. Iniciação à bioética [Internet]. Brasília: CFM; 1998 [acesso 5 fev 2021]. p. 37-51. Disponível: https://bit.ly/3cJHIQA

14. Moritz RD. A equidade e a não maleficência no cuidado de pacientes críticos terminais. Rev Bras Ter Intensiva [Internet]. 2009 [acesso 2 jun 2019];21(4):341-2. DOI: 10.1590/S0103-507X2009000400001

15. Conselho Federal de Medicina. Op. cit. 2019. p. 27.

16. Wanssa MCD. Autonomia versus beneficência. Rev. bioét. (Impr.) [Internet]. 2011 [acesso 15 jun 2019];19(1):105-6. Disponível: https://bit.ly/3tx0Uqz

17. Princípios bioéticos: a autonomia, não maleficência, beneficência, justiça e equidade. In: Conselho Regional de Medicina do Estado de São Paulo. Ética em ginecologia e obstetrícia [Internet]. São Paulo: Cremesp; 2002 [acesso 2 jun 2019]. Disponível: https://cutt.ly/3kxbUSx

18. Silva MAM. Penalidades aplicadas pelos Conselhos de Medicina. Conselho Regional de Medicina do Distrito Federal [Internet]. 16 jan 2018 [acesso 20 abr 2019]. Disponível: https://bit.ly/2OOJNRW

19. Callegari DC. Fui processado: o que devo fazer? J Cremesp [Internet]. 2009 [acesso 15 jun 2019];265:10. Disponível: https://cutt.ly/zkxQINm

20. Brasil. Decreto-Lei $n^{\circ} 2.848$, de 7 de dezembro de 1940. Código Penal. Diário Oficial da União [Internet]. Brasília, 31 dez 1940 [acesso 22 mar 2021]. Disponível: http://bit.ly/18kAHOG

Marina Faria Salomão - Graduanda - marinafariasalomao@gmail.com

(iD) 0000-0002-5076-1591

Luiza Ribeiro Gontijo - Graduanda - luiza.rg7@ hotmail.com

(iD) 0000-0002-6814-5789

Luisa Abdo Ramos Nunes - Graduanda - luluabdo@hotmail.com

(iD) 0000-0003-4175-2420

Felipe Pueyo Magalhães - Graduando - lipepueyo@gmail.com

(D) 0000-0001-6013-4295

José Helvécio Kalil de Souza - Doutor - jhkalil@gmail.com

(iD) 0000-0003-0914-0045

Roberto Paolinelli de Castro - Doutor - rpdecastro@uol.com.br

(D) 0000-0003-4487-5522

Correspondência

Marina Faria Salomão - Rua Agostinho Bretas, 130, Caiçara CEP 30775-520. Belo Horizonte/MG, Brasil.

Participação dos autores

Marina Faria Salomão, Luiza Ribeiro Gontijo, Luisa Abdo Ramos Nunes e Felipe Pueyo Magalhães analisaram dados e bibliografia sobre o tema e redigiram o artigo. José Helvécio Kalil de Souza e Roberto Paolinelli de Castro analisaram e aprovaram o texto e ajudaram a coletar dados nos conselhos regionais de medicina.

Recebido: 7.1 .2020

Revisado: 28.1 .2021

Aprovado: 29.1.2021 